\title{
Collective Intelligence and Entrepreneurial Resilience in the Context of Covid-19
}

\author{
Victor Mignenan $^{1}$ \\ ${ }^{1}$ Department of Management, University of Moundou (Chad) and member of the Carrefour d'Innovation et \\ d'Appui aux Entreprises laboratory, University of Quebec at Chicoutimi, Canada \\ Correspondence: Victor Mignenan, Department of Management, University of Moundou (Chad) and member of \\ the Carrefour d'Innovation et d'Appui aux Entreprises laboratoiry, University of Quebec at Chicoutimi, Canada.
}

Received: June 28, 2021

doi:10.5539/ibr.v14n9p1

\author{
Accepted: July 13, 2021 \\ Online Published: July 30, 2021 \\ URL: https://doi.org/10.5539/ibr.v14n9p1
}

\begin{abstract}
Research on the covid-19 pandemic, conducted to date, has clearly shown its negative impact on entrepreneurs. However, there are few relevant studies on the resilience of these entrepreneurs. Even economic stimulus packages developed by governments ignore collective intelligence, which is seen as an appropriate posture and path that can lead to the resilience of entrepreneurs in unpredictable situations. Thanks to the theoretical anchoring of collaborative management, we have developed and tested a conceptual model through the approach of deconstructing collective intelligence into (i) the sharing of capacities (ii) mutual aid (iii) collective competence and (iv) dynamic capacity. The data production was carried out through 15 semi-structured interviews and 282 surveys of Cameroonian and Chadian entrepreneurs. The results showed that mutual support $(\beta=0.32)$ and ability to share $(\beta=0.29)$ are indirectly the best predictors of economic and strategic entrepreneurial resilience. Because they participate effectively in building the collective competence of entrepreneurs in a context of crisis. This collective competence positively generates the level of variation in economic resilience $(\beta=0.38)$ and that of strategic resilience $(\beta=0.36)$. These results are the manifestation that covid-19 is boosting social dialogue between entrepreneurs. On the other hand, dynamic capacity appears less effective for the entrepreneurial economic resilience $(\beta=0.04)$ and strategic entrepreneurial resilience $(\beta=0.02)$ of the entrepreneurs studied due to the measures to combat covid-19. These findings contrast with previous research focused on entrepreneurial resilience through collective intelligence. They lead us to stress the importance of continuing research on the subject and to draw comparisons between entrepreneurs in crisis situations and those working in a stable ecosystem. The article is useful for researchers who find proven evidence that is more relevant. Then entrepreneurs will find new factors to make their entrepreneurial project viable. Finally, governments and their partners are urged to further promote entrepreneurship education based on dynamic capacity at the expense of confrontation and selfishness. Our article is part of the theory of collaborative management and organizational theory and reveals the existence of a relational contingency in the different stages of the entrepreneurial resilience process.
\end{abstract}

Keywords: resilience, collective intelligence, dynamic capacity, collective competence, collaborative management

\section{Introduction}

There are several studies (Leimeister, 2010; Levy, 2015; Malone \& Bernstein, 2015; Mulgan, 2018; Valencia, Roberto, \& Garcia, 2015) dedicated to collective intelligence, with a strong interest in the issue of dynamic capacity and sharing as preferred vectors to build collective competence and increase resilient posture in a complex situation (Akgüna \& Keskina, 2015; Alphonse-Tilloy \& Altintas, 2018; Altintas, 2015). These studies tend to show that collective intelligence has a positive influence on collective competence and promotes entrepreneurial resilience, particularly through dynamic peace, integration, sharing, etc. However, these studies focus exclusively on entrepreneurs operating in a quasi-stable ecosystem. Economic operators, in the context of the Covid-19 pandemic, with its government measures creating negative effects on the values of companies, are almost non-existent. In addition, the few results on entrepreneurial resilience because of collective intelligence, appear contradictory. Thus, as Recently pointed out by Love and Roper, it is not clear why, in a crisis such as Covid-19, some entrepreneurs are experiencing a considerable loss of value and others are not, when they are all 
subject to the same government measures (Love \& Roper, 2015). Considering the literature and the current pandemic, it is necessary to continue empirical studies to determine whether collective intelligence deserves to be integrated into the survival strategy of entrepreneurs in the context of change to make them more resilient.

In this perspective, we draw on the perspectives of collaborative management in the rest of the text to study the link between collective intelligence and entrepreneurial resilience, which, to our knowledge, is poorly integrated into previous empirical studies. Yet collaboration, sharing and collective capacities play an increasingly critical role in entrepreneurial resilience and collective intelligence participates well in its development.

We propose to test our hypotheses with a sample of 282 resilient entrepreneurs in four sectors of activity. Entrepreneurial resilience (ER in the rest of the text) are economic operators who keep their business running, despite, and this from their creation. The focus on ER echoes the fact that despite several shutdowns, some entrepreneurs maintain the operation of their business. Moreover, the choice of a sample of ER is justified by the inadequacy of empirical studies on this type of entrepreneur but also, the focus on ER is explained by the highly strategic nature of collective skills. Indeed, these entrepreneurs benefit from their dynamic capacity, sharing, mutual support that has fostered the emergence of collective skills and, indirectly, their economic and strategic survival.

The first part of this article will be devoted to the theoretical framework and the development of the framework presenting the portrait of the hypotheses of the research. Next, we will describe the methodological path based on both semi-structured interviews and the survey. Finally, we will present simultaneously the qualitative and quantitative results, followed by the discussions before concluding by mentioning the contributions of research and perspectives.

\section{Context and Theoretical Framework of Research}

Before presenting the hypotheses of our conceptual model, we will first describe respectively the context of Covid-19 and the theory of collaborative management to highlight its relevance to explain the model of entrepreneurial resilience through collective intelligence. Secondly, we will present the central concepts of research and the general theoretical framework.

\subsection{Context of Covid-19}

The covid-19 pandemic significantly reverses the progress made by stakeholders towards achieving the Sustainable Development Goals. The impact of the pandemic on the economy is disastrous (ONU, 2020) In Central African countries, the capacity of governments and their partners to implement economic support and recovery measures is limited (OIT, 2020) As governments and economic operators in Cameroon and Chad recover from the pandemic, the effects and costs of business losses are increasing. At the same time, many entrepreneurs are committed to building entrepreneurial resilience and promoting collective intelligence. This would lead to improvements in economic opportunities, including potential for new jobs. The Covid-19 pandemic has, perhaps, awakened collective intelligence and imposed resilient posture.

Cameroonian and Chadian entrepreneurs are disproportionately impacted by government measures, due to the inadequacy of dynamic capacity. The Covid-19 pandemic is amplifying gender inequalities between entrepreneurs (ONU, 2020) In both countries, the field of our research, women are over-represented in the agri-food, catering, etc. sectors, which are the most impacted by the Covid-19 lockdowns. Demonstrating the importance of collective intelligence could provide opportunities to address persistent business failures in Central Africa. Initiatives and organizations whose identification, design and management are based on collaborative posture have played a key role in survival but also in combating the impact of the pandemic (OIT, 2020; PNUD, 2020).

This research, carried out as part of the 88th Acfas, aims to promote the benefits of collective intelligence as responses to the revival and revitalization of the more inclusive and sustainable economic sector in Cameroon and Chad. It results from the analysis of data and evidence, including the use of an appropriate mix of economic opportunity methodologies in Covid-19 responses. The objective of this study is to contribute to responses to the Covid-19 pandemic in Central Africa.

\subsection{Collaborative Management}

It is a posture of action in the real field of maneuver that surpasses the individual action. It is part of a dynamic of collective action around which an organized team of actors directs and negotiates its collective interactions towards a goal that each member is aware could not be achieved by a single actor (Henri \& Lundgren-Cayrol, 2001) Individual contributions therefore only make sense of their total integration, their global fusion and not by mere juxtaposition. In other words, it is a question, for each actor/stakeholder of an entrepreneurial initiative or 
project, of feeding his individual contributions by those of the other collaborators. Therefore, the posture of collaborative management implies the mutual commitment of the actors, stakeholders in the action. This commitment is the result of a will and a coordinated effort to reflect, effectively carry out a task, solve a problem together or bring out a relevant solution in the context of complexity.

Collaborative management is thus characterized by a stronger interactivity of the actors and requires more motivation and interpersonal trust. The relevant values of human capital (trust, motivation, solidarity, respect, etc.) (Mignenan, 2020a) are pillars of the deployment and success of this management mode. It should be stressed that this management style be the best trajectory that can lead to the achievement of performance in terms of creativity, responsiveness, mobility, adaptation of the unexpected or optimized use of the means made available. Moreover, this ability of a team to value its human capital and its relational capital is part of a collective intelligence. Be that as it may, the success of collaborative management is based on the construction of a common understanding around the activities carried out and therefore shared knowledge resulting from the contribution of each of the members.

\subsection{Collective Intelligence and Entrepreneurial Collective Competence}

According to several studies, to bring out collective skills and resilient entrepreneurship, entrepreneurs need to: (i) pool individual assets and talents (ii) share knowledge and ideas (iii) direct knowledge towards relevant objectives or issues (iv) support each other in order to bring out innovative solutions (Bernard \& Barbosa, 2016; Malone \& Bernstein, 2015; Mulgan, 2018) this is the manifestation of collective intelligence. Indeed, for a large number of authors (Leimeister, 2010; Malone \& Bernstein, 2015; Mulgan, 2018; Valencia et al., 2015; Woolley, Aggarwal, \& Malone, 2015) collective intelligence (CI) refers to a system and approach that combines, in a coordinated manner, the collective strengths of individuals in terms of skills, knowledge and problem-solving abilities. However, other work reveals that collective intelligence, as a determinant of entrepreneurial resilience, emerges from three types of integrated intelligence namely (i) intellectual intelligence (cognitive mind); (ii) emotional intelligence from the mind and (iii) relational and systemic intelligence (synchronized collaboration with people around them) (Valencia et al., 2015; Woolley et al., 2015; Zaïbet, 2007) However, for other authors, the modeling of resilient collective intelligence $(\mathrm{RCI})$ is essentially based on three principles: the dynamic integrity of entrepreneurs; transparency; the integration of assets and talents; and the commitment (responsibility) of entrepreneurs. The examination of these three principles made it possible to group effective collective intelligence for entrepreneurial resilience into three postures: (i) entrepreneurial collective intelligence (Ünay \& Zehir, 2012) (ii) innovative collective intelligence (Saur-Amaral, 2010; Ünay \& Zehir, 2012) and intelligence execution collection

In the same perspective as resilient entrepreneurship, several authors (Brulhart, Favoreu, \& Loufrani-Fedida, 2019; Mulgan, 2018; Valencia et al., 2015; Woolley et al., 2015) reveal that collective intelligence fertilizes collective competence and pursues four fundamental objectives: (i): to generate increased performance (ii) to facilitate wiser decision-making (iii) to generate new ideas (iv) to co-construct creative solutions. There are three ways to achieve this: (i) sharing/exchanging information and ideas to find resonances; ii) spread knowledge/action towards a specific problem or objective; (iii) converge and join to provide mutual support and generate innovative solutions. It is in this perspective that Lévy believes that ICR, as "ecosystems of ideas" and cognitive collaboration, would be the greatest wealth of the living universe (Levy, 2015; Lévy, 2003)

By crossing the above types, objectives, and methods of CI, it emerges: (i) entrepreneurial collective intelligence that manifests itself in (a) mutual support, (b) sharing capacity; (ii) innovative collective intelligence which concerns (c) collective competence and (d) collaboration for the transformation of knowledge from all disciplines. Like other authors before us (Amhag \& Jakobsson, 2009; Bernard \& Barbosa, 2016; Carlier, 2016; Saur-Amaral, 2010) we mobilize the theory of collaborative management which is particularly useful for building and testing the model of entrepreneurial resilience through collective intelligence. Thus, our model is based on the premise that entrepreneurial resilience in complex situations depends on the collective competence produced by the ICR, which constitutes the strategic resources of entrepreneurs. In this context, it is expected that collective intelligence, through its three components, acts on collective skills and, ultimately, on entrepreneurial (economic and strategic) resilience. The theory of collaborative management, therefore, makes it. 


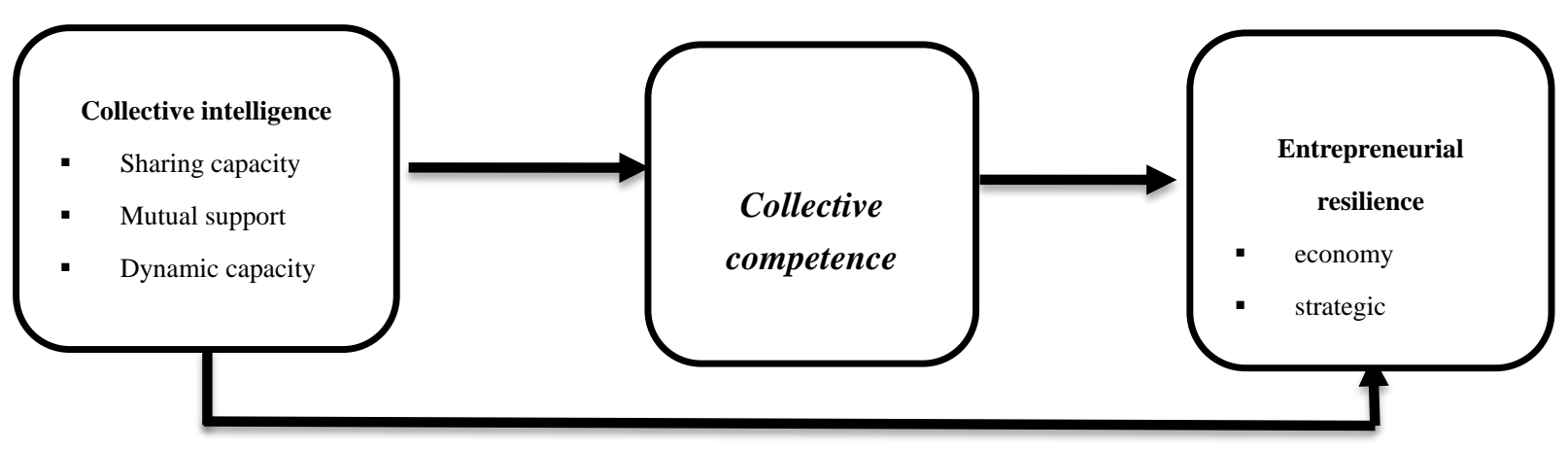

Figure 1. Conceptual framework for entrepreneurial resilience

Source: literature compilation (author, 2021)

\subsection{Collective Skills and Entrepreneurial Resilience}

It is generally accepted that what makes a community strong is its ability and willingness to work together and that this depends not only on a relevant management of skill profiles, but also on a mobilization of energies. Studying collective competence means, as a recent study (Chédotel \& Krohmer, 2014) a broader interest in the coordination of activities by individuals in problem situations. In this perspective, collective competence is represented in the form of a set of resources from which the actors of the mobilized collectives will draw. If collective competence is a stock of ways of acting, behaviors and ways of thinking that evolve in processual ways according to successive interactions, we are entitled to ask ourselves what concrete forms can these resources take in the context of the crisis caused by the covid-19 pandemic? And how are they used for the benefit of entrepreneurship by actors? Also, for a large number of works (Defélix, Boulaire, Monties, \& Picq, 2014; Leimeister, 2010; Omrane, Fayolle, \& Ben-Slimane, 2011) who demonstrate, in a very relevant way, what a collective competence can look like (shared representation, operative common language, trust), are also more discreet about their construction dynamics which is, in our opinion, of a communicational nature.

Great interest has been shown in building the skills of entrepreneurs. The skills of entrepreneurs in the context of a crisis are an important resource that facilitates the resilience of SMEs (Brulhart et al., 2019) and are an integral part of the survival process. Dupuich (2011) argues that the disappearance of some SMEs during previous crises is due to the fact that some entrepreneurs operate in a vacuum and are therefore not integrated into relevant business networks. This finding is confirmed by a longitudinal study (Ayala \& Manzano, 2014) conducted empirically among SMEs. Thus, entrepreneurs who evolve in a position of confrontations have difficulty, from the start of their activity, to bounce back at the slightest shock than entrepreneurs who build business networks. In the literature on entrepreneurship, several authors (Omrane et al., 2011) point out that collective competence encompasses all shared representations, common operative languages, close and lasting trusts or, more broadly according to other authors (Malone \& Bernstein, 2015; Matlay \& Westhead, 2007; Mulgan, 2018). With regard to entrepreneurial projects, only skills that bring at least a minimum of value to the company are considered as relevant skills, i.e., as a potentially strategic resource. To provide such value, these skills must have certain characteristics (Leimeister, 2010; Lévy, 2003) First of all, skills are based on know-how and know-how, the pooling of capacities. The pooling aspect is therefore important and will facilitate the identification of more relevant entrepreneurial projects, i.e., projects "that respond to the specific problem. Similarly, the notion of collective also appears fundamental. Finally, the pooling of forces, capacities and means is marked by a long-term, effective or sought-after logic, an element emphasized both in the application of the concept of intelligence and in entrepreneurial resilience. On the basis of this reasoning, collective competence can be defined as the set of organizational, technical and strategic assets of economic operators marked by the trust, respect, reciprocity and commitment of the partners. We will see that this, in addition to being decisive for the rebound and survival of the company in a crisis situation, can be strengthened by collective intelligence.

Resilience was, initially, conceptualized in the field of ancient physics, then, in the work in psychology. Since then, specialists in the social sciences have integrated resilience to reveal a profusion of studies, in economics, management, education, etc. In general, several authors (Ayala \& Manzano, 2014; Bernard \& Barbosa, 2016; Davoudi, 2013) believe that the manifestation of resilience could take into account two dimensions: (i) the presence of adversity manifesting the strong threat accompanied by significant stress, trauma, and (ii) positive adaptive posture characterized by a rebound, evolution, despite the apparent risks (Bernard \& Barbosa, 2016) A 
large number of authors reveal the different facets of resilience, which include cognitive ability and personality trait that relate to positive ability to adapt to risky or highly stressful situations (Akgüna \& Keskina, 2015; Ayala \& Manzano, 2014; Walker \& Cooper, 2011) In the field of entrepreneurship, to evoke entrepreneurial resilience, literature puts forward traits, skill, quality. Other works evoke reactions to entrepreneurial failure, stress, resistance, to characterize entrepreneurial resilience (Akgüna \& Keskina, 2015; Ayala \& Manzano, 2014). According to Davoudi, entrepreneurial resilience can be interpreted as a structure of opportunities for entrepreneurs, characterized by a sense of rebound (Davoudi, 2013) For this author, entrepreneurs act as agents of change proposing and implementing innovative solutions to remedy and mitigate the consequences of crises. Other authors (Leimeister, 2010; Mulgan, 2018) argue that: (i) entrepreneurial resilience stems from a complex interaction of many factors and the contribution of each of the factors and (ii) entrepreneurial resilience is multidimensional and emerges from the common perspectives of several interacting stakeholders.

On the other hand, entrepreneurial resilience manifests itself in overcoming adversities, adapting to uncertainty and learning through failure. Work on resilient entrepreneurs looks at the levels of business success between resilient and non-resilient entrepreneurs (Ayala \& Manzano, 2014) or how resilient entrepreneurs adapt to change and bounce back in difficult circumstances (Bullough, Renko, \& Myatt, 2014) As entrepreneurs are exposed to the risk of failure and uncertainty, entrepreneurial resilience is the key to their ongoing trials and success. However, in the context of this research, the critical review of the literature leads us to have the following concern about entrepreneurial resilience: research on entrepreneurial resilience did not take into account the principles and methods of the collective intelligence of entrepreneurs. The second concern is the lack of a holistic perspective on entrepreneurial resilience. As a result, we note that entrepreneurial resilience implies the following characteristics: (i) the ability to bounce back from an adverse event (Akgüna \& Keskina, 2015) (ii) the ability to cope with major disruptive events (Boder, 2006) (iii) the ability to adapt to a difficult environment (Davoudi, 2013) (iv) the tenacity to survive and make success (Burnard \& Bhamra, 2011) These characteristics are operationalized, for the purposes of this research, into (a) entrepreneurial economic resilience and (b) strategic entrepreneurial resilience.

\subsection{Development of Research Hypotheses}

\subsubsection{Collective Competence Because of Mutual Support and Sharing Capacity}

Centered on formal interaction characterized by common languages, agreements and compromises with the aim of promoting consensus around definitions relating to a project of change, mutual support (SM) concerns the supports, the posture of solidarity and the strategy of their deployment (Foudriat, 2014). The dynamic capacity (DC) focused on solidarity in times of crisis is particularly beneficial for economically and strategically resilient entrepreneurship. Indeed, entrepreneurs, in the context of a crisis, despite different interests and points of view, will gain more from conducting joint reflections and pooling energies. Entrepreneurs in the context of covid-19 have an interest in using collective know-how to "maintain activities in a way that creates value. The capacity to share $(S C)$ through interaction, the sharing of experience or other manifestations, allows bringing out common capacities and promotes the survival of business.

Following the model developed in Figure 1, several empirical studies (Leimeister, 2010; Levy, 2015; Valencia et al., 2015; Woolley et al., 2015) conclude, overall, that each characteristic of DC and SC participates in the emergence of a collective competence. Based on this research and the analytical framework suggested in Figure 1, we formulate the following first research hypothesis:

\section{$>$ Hypothesis 1 (HI): mutual support (Hla) and sharing capacities (HIb) increase collective competence.}

\subsubsection{Dynamic Capacity and Entrepreneurial Resilience}

The dynamic capacity (DC) of a team or organization is an approach that is based on the evolution of resources and skills (Alphonse-Tilloy \& Altintas, 2018; Mathé, 2006; Remon, 2012) to respond to an uneasy stable ecosystem. For some authors, it's the skills of a team or organization to be able to integrate, build and reconfigure its internal and external skills in order to cope with the instability of the environment (Altintas, 2015; Mathé, 2006; TEECE, PISANO, \& SHUEN, 1997) This dynamic capacity emerges from two theoretical perspectives, in particular (i) the evolutionary approach, rooted in the theories of organizational evolution and characterized by organizational factors and (ii) the entrepreneurial approach, based rather on managerial factors and place managers at the center of the emergence of dynamic capacities as a heritage of survival and sustainability. It is this last perspective that we take to appreciate entrepreneurial resilience.

Thus, from the managerial perspective, dynamic capacity is associated with performance and competitiveness but also with the survival of companies (Alphonse-Tilloy \& Altintas, 2018) Similarly, they manifest themselves 
in the achievement of objectives, results and co-responsibility (Mathé, 2006; Pquet, 2009) Dynamic capacity requires team members to have greater interactivity, intensive mutual engagement of stakeholders in a concerted effort (Pquet, 2009) require more resources and interpersonal trust (Amhag \& Jakobsson, 2009) The human factor (trust, motivation, solidarity, respect, etc.) becomes central to this strategic posture. This intelligent mode of action makes it possible to achieve better performance in terms of responsiveness, survival, adaptation of the unexpected or optimized use of the resources allocated to the entrepreneurship project (Alphonse-Tilloy \& Altintas, 2018; Matlay \& Westhead, 2007) Moreover, this ability of a group to enhance its human capital (Mignenan, 2020a) is part of a collective active capacity that generates entrepreneurial resilience. Part of the success of dynamic capacity will be in particular the construction of a common understanding around the activities carried out and therefore shared knowledge resulting from the contributions of each of the entrepreneurs. Therefore, through dynamic coping mechanisms, entrepreneurs are looking for resources, reorganizing them to improve their productive efficiency and achieve a high level of survival (Altintas, 2015; Boutigny, 2004; Remon, 2012). On the basis of this reasoning, the following second hypothesis is formulated.

$>$ Hypothesis $2(\mathrm{H} 2)$ : Dynamic capacity positively influences entrepreneurial economic resilience $(\mathrm{H} 2 \mathrm{a})$ and strategic entrepreneurial resilience $(H 2 b)$.

\subsubsection{Collective Skills and Entrepreneurial Resilience}

Several authors have shown that entrepreneurs who have developed collective skills, from the start of their business, consolidate economic sustainability and strategic rebound (Defélix et al., 2014) The economic and strategic success of the company is then based, at the same time, on the pooling of resources and the common heritage of entrepreneurs (Dufresne \& Peyrat-Guillard, 2009) According to the authors, the capacity that emerges from a collective of entrepreneurs is more effective, more agile than the competence of a single consultant. In fact, the collective competence of entrepreneurs or the dynamic combination of individual abilities are often unique, which makes them valid, rare and difficult to bring out (Brulhart et al., 2019) In addition to being unique, collective competencies are causally ambiguous and socially complex. Thus, pulling the skills of several entrepreneurs can be an important source for identifying new markets and strategic positioning in a sustainable competitive environment (Brulhart et al., 2019; Defélix et al., 2014) and therefore economic and strategic performance (Brulhart et al., 2019) Numerous empirical studies (Boutigny, 2004; Defélix et al., 2014; Dufresne \& Peyrat-Guillard, 2009; Dupuich, 2011) confirm this by showing the influence of collective skills, both on economic performance and on strategic performance. Overall, collective competence, understood in the form of added value, is recognized as essential for entrepreneurial resilience (Boutigny, 2004; Brulhart et al., 2019) and more particularly in the context of crisis (Boutigny, 2004) In this sense, some authors (Dufresne \& Peyrat-Guillard, 2009; Dupuich, 2011) have shown that the fact that entrepreneurs belong to mutual solidarity contributes significantly to the survival of their income-generating activity.

Collective competence also influences the strategic entrepreneurial resilience of companies. In general, the success of entrepreneurs in a crisis context depends strongly on the quality of their ability to analyze, collectively formulate a solution and especially to experiment with it (Chédotel \& Krohmer, 2014) The promotion of open reflection and in a network of communities leads to the discovery and creation of business opportunities that are almost impossible to identify without the participation of employees or any other relationships (Chédotel \& Krohmer, 2014; Defélix et al., 2014) This is also why collective business skills foster the creation of unprecedented competitive advantages (Brulhart et al., 2019; Dufresne \& Peyrat-Guillard, 2009) This has been shown by several studies carried out in the context of the crisis. More recently, some work (Brulhart et al., 2019; Defélix et al., 2014; Dupuich, 2011) on start-ups, revealed that the collective competence between various actors such as sales, marketing, human resources, IT, hospitality, etc. agents play an important role, both, in identifying and exploiting opportunities. These authors tested the direct link between this skill and the exploitation of opportunity and showed that the more entrepreneurs pool their knowledge, interact dynamically, the greater and lasting the identification, mastery and exploitation of new opportunities that bring economic values. The literature on entrepreneurial resilience, apart from its application to the context of crisis, recognizes that collective competence is a lever of creativity, efficiency and mobility and therefore has a strong explanatory power to explain the survival of business (Brulhart et al., 2019; Woolley et al., 2015) In light of these relationships, we formulate the following hypothesis 3 :

Hypothesis 3 (H3): Collective competence positively influences entrepreneurial economic resilience $(\mathrm{H} 3 \mathrm{a})$ and strategic entrepreneurial resilience $(H 3 b)$. 
By way of synthesis, Figure 2 gives an account of the framework of research hypotheses.

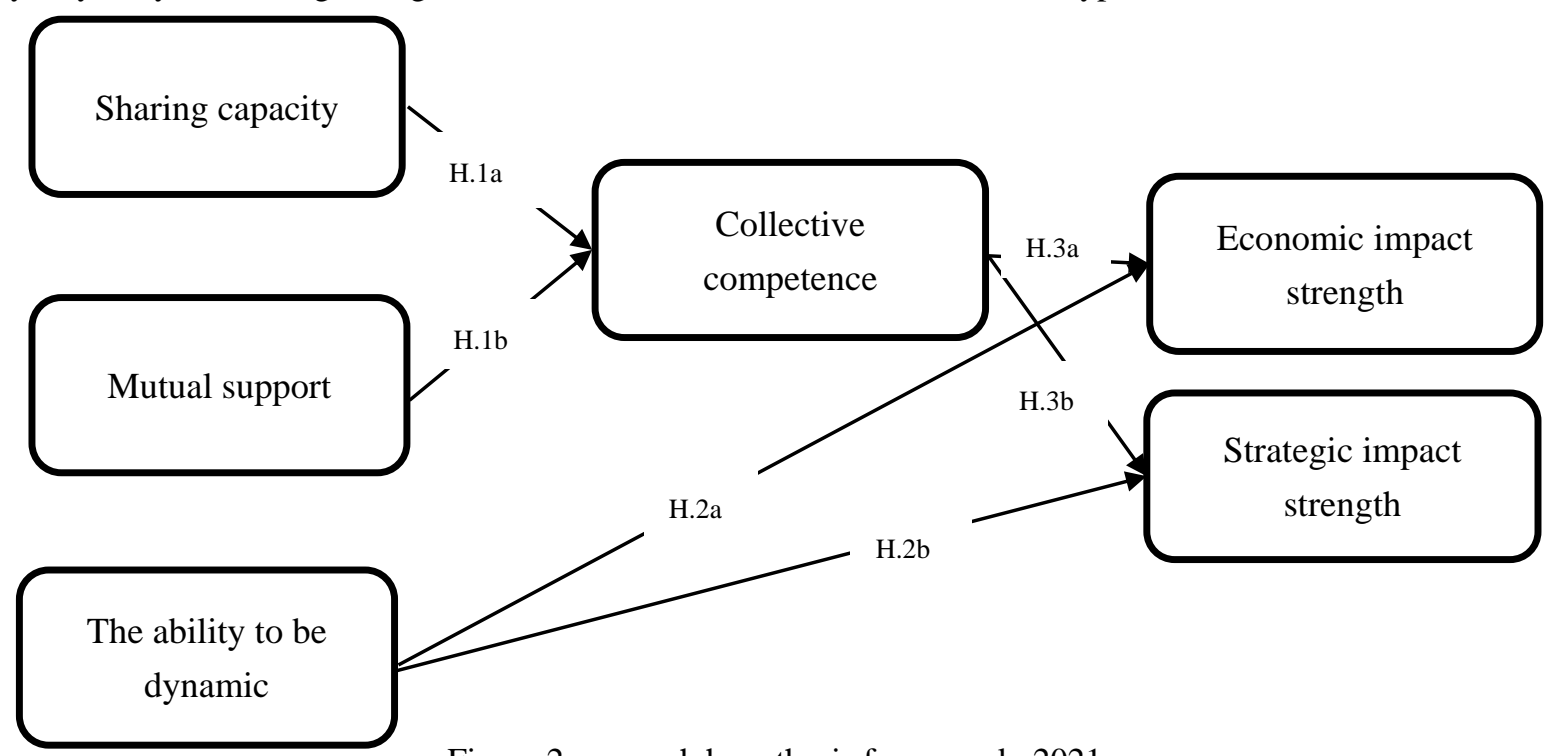

Figure 2. research hypothesis framework, 2021

Source: Compiled literature data (author, 2021)

To validate these hypotheses, the sequence below gives an account of the methodological path.

\section{Methodological Process}

This research was based on the perspectives of collaborative management (Carlier, 2016) and adopted an integrated approach to entrepreneurial resilience. Although management remains collaborative rather un-circumscribed, this theoretical foundation has made it possible to understand how entrepreneurs with collective intelligence can manage to set up activities capable of rebounding, surviving and succeeding despite government measures to combat the covid-19 pandemic. Since it is a question of interpreting the behavior of entrepreneurs in a complex context, the interpretation design is well suited.

\subsection{Approach}

To produce the data, we applied the mixed strategy of the fact that collective intelligence and entrepreneurial resilience are built with multidimensional, but also interdisciplinary characteristics. More specifically, the mixed approach (Creswell, 2013), simultaneously deploying qualitative and quantitative methods, was used.(Creswell, 2013)

Thus, in the first place, the documentary search was carried out. It thus made it possible to understand the various facets of the main variables (collective intelligence, collective competence, and entrepreneurial resilience) under study. The literature explored has made it possible to: (i) paint a portrait of the theoretical framework and the conceptual model, and (ii) understand the currents of theoretical thought that underlie collective intelligence and entrepreneurial resilience.

Second, we conducted the semi-directive interviews, widely advocated in management sciences (Evrard et (Evrard et al., 2009)

The conduct of the interviews is preceded by the development of the semi-directive interview guide. This one, taking the place of common thread, was built with the help of the information generated from the relevant literature. Six themes below are broken down and formulated in the form of open-ended questions:

\footnotetext{
$\checkmark \quad$ Theme 1: Sharing Capacity (CP).

$\checkmark$ Theme 2: Mutual Support (DM).

$\checkmark$ Theme 3: Dynamic Capacity (CD)

$\checkmark$ Theme 4: Collective Competence (CC).

$\checkmark \quad$ Theme 5: Economic Entrepreneurial Resilience (EER)

$\checkmark \quad$ Theme 6: Strategic Entrepreneurial Resilience (SER)
} 
The contractors were easily familiar with the six themes of the interview. This facilitated the obtaining of information and the achievement of the saturation threshold after having carried out the 13th interview, in the cities of Doba, Moundou, N'Djamena and Sarh (for Chad) and Maroua, Kousséri, Touboro and Ngaoundéré (for Cameroon) during the months of January to April 2020 with an average duration of 30 minutes per respondent. Table 1 shows the characteristics of interview respondents.

Table 1. Characteristics of interview respondents

\begin{tabular}{|c|c|c|c|c|c|c|}
\hline \multicolumn{7}{|c|}{ Information about the interviewees } \\
\hline The sector & $\begin{array}{l}\text { Average } \\
\text { size }\end{array}$ & $\begin{array}{l}\text { Date/period } \\
\text { interview }\end{array}$ & $\begin{array}{l}\text { Average } \\
\text { duration }\end{array}$ & $\begin{array}{l}\text { Seniority in } \\
\text { the position }\end{array}$ & Category & $\begin{array}{l}\text { Number of } \\
\text { interviewees }\end{array}$ \\
\hline Dairy products & 51 & \multirow{4}{*}{$\begin{array}{l}\text { January to April } \\
2020\end{array}$} & $\begin{array}{c}31 \\
\text { minutes }\end{array}$ & $7-15$ & Chief of Staff & 4 \\
\hline Oil, beverages & 201 & & $\begin{array}{c}29 \\
\text { minutes }\end{array}$ & $5-11$ & $\begin{array}{c}\text { Director of } \\
\text { Human Resources }\end{array}$ & 3 \\
\hline Pasta, & 37 & & $\begin{array}{c}28 \\
\text { minutes }\end{array}$ & $4-9$ & \multirow[b]{2}{*}{ Managers } & 4 \\
\hline $\begin{array}{l}\text { cosmetics, and } \\
\text { pharmacy }\end{array}$ & 8 & & $\begin{array}{l}30 \\
\text { minutes }\end{array}$ & 1 to 15 years & & 4 \\
\hline
\end{tabular}

Source: Compiled interview data (author, 2021)

The analysis techniques focus mainly on lexical analysis and thematic content analysis. Table 2 presents the two qualitative techniques that were applied.

Table 2. Analytical techniques

\begin{tabular}{|l|l|l|}
\hline Nature of qualitative analysis & Components & Relevance indicators \\
\hline Lexical & Words used, sentences. & $\begin{array}{l}\text { Type and quality of vocabularies used. } \\
\text { e.g.: frequency of appearance of words, the average number } \\
\text { of words per sentence, etc. }\end{array}$ \\
\hline thematic & $\begin{array}{l}\text { Sentences, paragraphs, } \\
\text { themes }\end{array}$ & $\begin{array}{l}\text { Thematic breakdown } \\
\text { e.g.: frequency of appearance of themes, frequency of } \\
\text { association }\end{array}$ \\
\hline
\end{tabular}

Source: Inspired by Evrard et al., 2005

Lexical analysis and thematic content analysis have made it possible to bring out new facets of collective intelligence, from collective competence as having an explanatory power over entrepreneurial resilience. The results also made it possible to validate the dimensions of collective intelligence and entrepreneurial resilience. In addition, lexical analysis and content analysis have helped to identify the concepts regularly evoked by responsible entrepreneurs to shed light on the manifestation of collective intelligence as having played a decisive role in the survival of companies.

Thirdly, it is the quantitative step that is based on the hypothetico-deductive posture. Three hypotheses were formulated following the analysis of the relevant literature. The choice of the hypothetico-deductive approach favored the validation of the explanatory power of collective intelligence on entrepreneurial resilience. It is also justified by the fact that little research has adopted such a posture. To generate the data, we conducted surveys using face-to-face or online surveys (on a five-point Likert scale) from January to April 2020. The elaboration of the items preceded the design of the questionnaire, which is essentially composed of the different facets of collective intelligence, of collective competence that emerges from the reports supplemented by the exploitation of literature. The questionnaire designed was pre-tested with 30 resilient entrepreneurs. These managers were chosen on the basis of criteria of expertise in the creation and management of SMEs in Cameroon and Chad.

The process of determining the sample size is based on the recommendations of Igalens and Roussel (1998). According to these two authors, the sample size must be proportional to the number of items: 5 to 10 times more 
samples than there are items presenting the constructs under study. In total, 39 items were defined to appreciate the six built. Thus, we have $5 \times 39$ and $10 \times 39$, that is between 195 and 390 . We opted for 390 contractors, which were considered reporting units. The 390 entrepreneurs are promoters of SMEs in six sectors of activity. The questionnaire was sent through two research firms, which distributed, monitored, and collected it. The people who filled it out were entrepreneurs who had been active for at least two months but also those who failed due to government measures related to Covid-19. After four reminders, a total of 282 questionnaires were received; or $72.30 \%$ of them were used in the analysis. Table 3 presents the characteristics of the enterprises in the field of this research.

Table 3. Characteristics of the sample

\begin{tabular}{|c|c|c|c|c|}
\hline \multirow[t]{2}{*}{ The sector } & \multirow{2}{*}{$\begin{array}{l}\text { Average } \\
\text { size (N) }\end{array}$} & \multicolumn{3}{|l|}{ sample } \\
\hline & & Size & Hierarchical level & $\begin{array}{l}\text { Experience } \\
\text { (in years) }\end{array}$ \\
\hline Dairy products & 26 & 10 & \multirow{4}{*}{$\begin{array}{l}\text { Promoters, partners and } \\
\text { others }\end{array}$} & \multirow[t]{4}{*}{1 to 10} \\
\hline Fruit jams & 25 & 10 & & \\
\hline pasta & 22 & 10 & & \\
\hline bakery & 24 & 10 & & \\
\hline vegetable oil & 75 & 3 & \multirow[t]{4}{*}{ Shareholders } & \multirow{8}{*}{1 to 15} \\
\hline Alcoholic and carbonated beverages & 62 & 5 & & \\
\hline mineral water & 53 & 3 & & \\
\hline sugar bowl & 63 & 2 & & \\
\hline Shea butter & 27 & 20 & \multirow{4}{*}{$\begin{array}{l}\text { Entrepreneurs/economic } \\
\text { operators }\end{array}$} & \\
\hline peanut butter & 29 & 25 & & \\
\hline \multirow[t]{2}{*}{ Cosmetics, transportation, pharmacy, restaurants } & 302 & 172 & & \\
\hline & 708 & 282 & & \\
\hline
\end{tabular}

Source: Compiled survey data (author,2021)

\subsection{Variables and Measures}

The measures recommended in this research are based on previous qualitative and quantitative studies (Altintas, 2015; Brulhart et al., 2019; Mathé, 2006; Pierre \& Fernandez, 2018; Remon, 2012; Samiha \& Brahim, 2020; TEECE et al., 1997; Ünay \& Zehir, 2012; Valencia et al., 2015; Woolley et al., 2015) We have adapted them to Cameroonian and Chadian entrepreneurs.

\section{Independent Variables}

To measure independent variables, we mobilized interview and literature indicators (Brulhart et al., 2019; Samiha \& Brahim, 2020; Ünay \& Zehir, 2012; Valencia et al., 2015; Woolley et al., 2015)

$\checkmark$ For mutual support (MH), the preferred indicators are: (i) capacity for collaboration (ii) levels of mutualization; (iii) opportunities for support; (iv) level of trust and sharing; (v) presence of collaborative platform (vi) collaborative spaces (vii) possibility of crowdfunding (viii) motivation for cooperative entrepreneurial action (ix) existence of the pragmatism of entrepreneurs.

$\checkmark$ With respect to sharing capacity, we selected the following indicators: (i) joint experimentation with renewed approaches; (ii) membership in business networks; (iii) the presence of a space for the exchange of knowledge (iv) support actions for accompanying persons, (v) the level of pooling of knowledge (vi) the collective capacity of the creative imagination (vii) the joint manufacture of new goods (viii) the joint use of new production methods (ix) the level of joint implementation of new methods of work organization.

$\checkmark$ For dynamic capacity, we opted for: (i) spirit of synchronization of ideas and resources; (ii) behavior centered on the reorganization of resources and mutual trust; (iii) presence of frameworks for the exchange of experience and information; (iv) promotion of the work collective and (v) promotion of teamwork.

For collective competence, the focus is on: (i) collective management capacity of distribution; (ii) mastery of collective production management methods; (iii) existence of trade and marketing profiles; (iv) existence of finance profiles, (v) existence of action plan; (vi) level of knowledge of market developments (vii) existence of shared vocabularies of collaborative work (viii) existence of shared memory (ix) existence of a reference system and common rules.

These indicators are measured through the five-point Likert scales [ranging from [1] strongly disagree to [5] strongly agree]. The alpha reliability (Cronbach coefficient) of the scale's ranges from 0.92 to 0.94 . 


\section{Dependent variable (entrepreneurial resilience)}

For entrepreneurial economic resilience, the main indicators selected are: (i) an increase in economic value; (ii) the evolution of turnover; (iii) increase in sales.

For strategic entrepreneurial resilience, we recommended the following indicators: (i) acquisition of new markets; (ii) emergence of new needs.

Responses were obtained using a Likert scale [ranging from [1] strongly disagree to [5] strongly agree]. The alpha reliability of the scale is 0.79 .

\section{Results, Discussion and Implications}

\subsection{Results}

Qualitatively, we have highlighted the full reports initially generated. The main opinions on the Covid-19 pandemic and those related to collective intelligence as a determinant of the survival or failure of Cameroonian and Chadian entrepreneurs. Table 4 provides a portrait of these reports.

\section{Major trends in entrepreneurs' opinions on the covid-19 pandemic}

\section{What are your views on the impact of the Covid-19 pandemic on entrepreneurship?}

Like entrepreneurs in other countries, the Covid-19 pandemic has been particularly significant for Cameroonian and Chadian entrepreneurs. Firstly, entrepreneurial activity, in itself, is already at risk of success or loss, and we have seen the measures put forward for the continuation of our economic activities.

\section{What measures should be put in place to reinvigorating entrepreneurship?}

Measures in entrepreneurial education such as training in the identification, design, financing and management of entrepreneurial activities are relevant axes. We know that the closure of businesses has led to a drop in motivation for almost $60 \%$ of entrepreneurs. Since the low turnover and the decrease in motivation are linked to a higher risk of abandonment or change of profession, it is likely that the government measures put in place also contribute to the increase in the loss of values of companies. These effects could be observed in entrepreneurs who are already at high risk, but also in entrepreneurs who are not at risk but who are vulnerable to the changes brought about by the pandemic. Entrepreneurial failure is often associated with innovation, isolation and management.

Table 4. Full reports

\begin{tabular}{|c|c|}
\hline & Full reports \\
\hline & 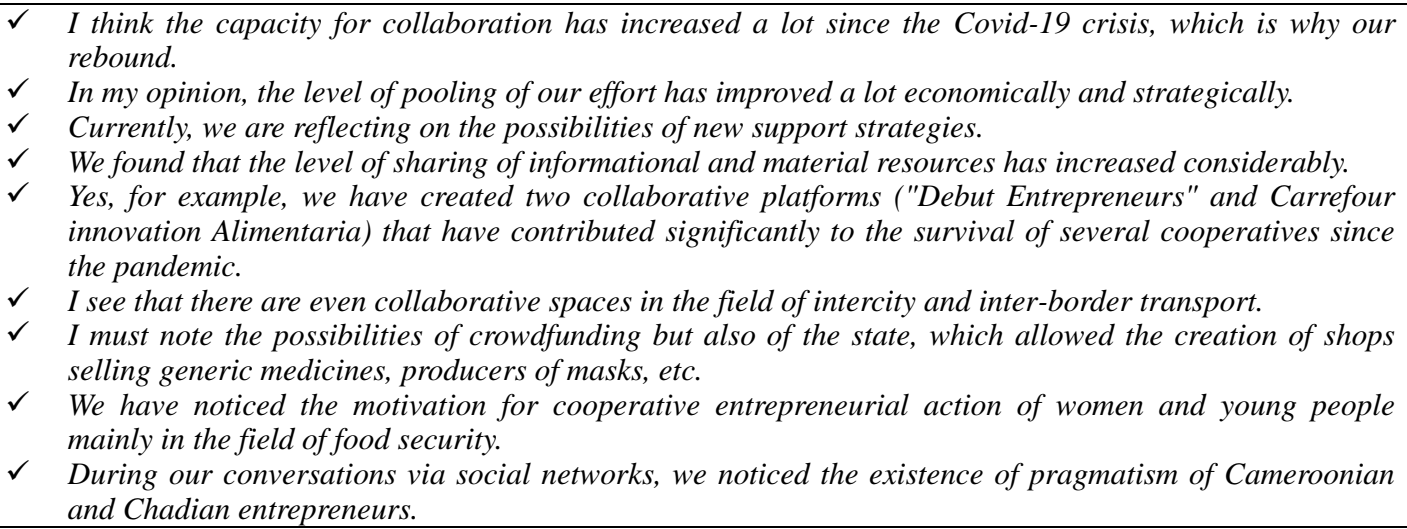 \\
\hline & $\begin{array}{l}\checkmark \quad \text { I note common experiments with shared approaches in production, distribution and sales strategy. } \\
\checkmark \quad \text { The phenomenon of Covid-19 is ensuring that all entrepreneurs express a desire to share and belong to } \\
\text { business networks; I can mention the network of producers of honey, shea butter, soya, thrift store sales, } \\
\text { etc., which brings together more than } 300 \text { members in Chad and Cameroon. } \\
\checkmark \quad \text { In the coming days, we plan to set up spaces for the exchange of knowledge and experience in the field of } \\
\text { creation and management of food cooperatives, food savannas, food greenhouses, etc. } \\
\text { There are collectives for support actions of the accompanists for new and entrepreneurs in financial, } \\
\text { organizational and strategic difficulties; this collective has helped save more than } 5 \text { SMEs since } \\
\text { Covid-19. } \\
\checkmark \quad \text { What I see during Covid-19 is the level of pooling of knowledge of entrepreneurs. } \\
\checkmark \quad \text { In my opinion, the collective capacity of the creative imagination in productive and distributive flows has } \\
\text { improved in the sector of restaurants, bars, intercity transport, etc. } \\
\text { I note the joint manufacture of new goods in the strategies to combat Covid-19: portable fountains, seals }\end{array}$ \\
\hline
\end{tabular}




\begin{tabular}{|c|c|}
\hline & $\begin{array}{l}\text { for hygienic use, masks, etc. } \\
\checkmark \quad \text { For my part, I note the joint use of new production and sales methods in the Agri-foodstuff sector. } \\
\checkmark \quad \text { For us, this is the level of joint implementation of new methods of work organization, in particular the } \\
\text { opening and closing hours of shops and other ancillary places. }\end{array}$ \\
\hline & 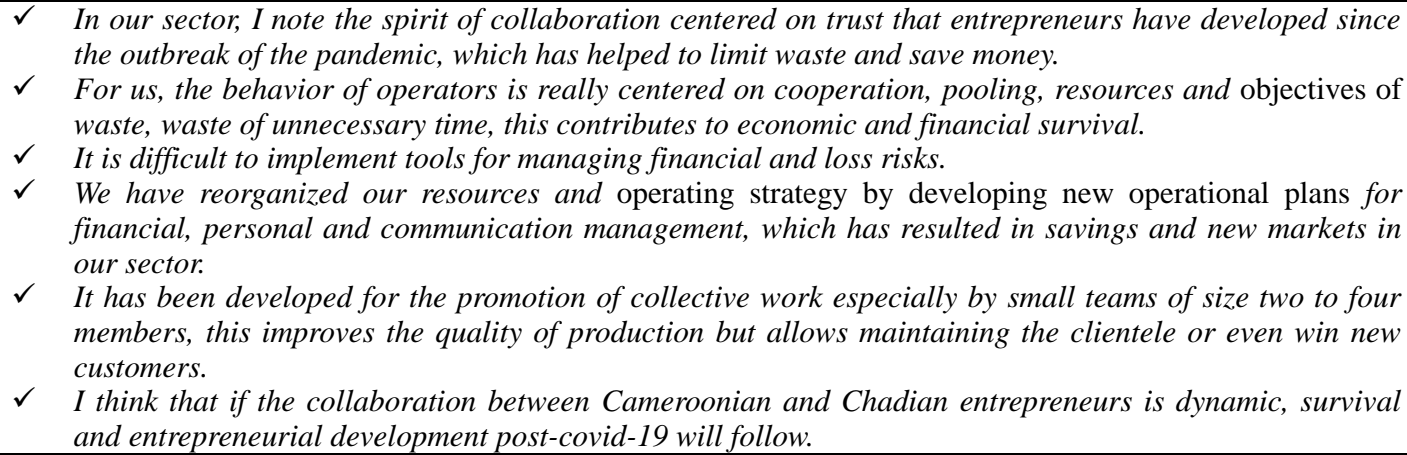 \\
\hline & $\begin{array}{l}\checkmark \quad \text { As a team, we have significantly improved the distribution management capacity and therefore our } \\
\text { circuit. } \\
\checkmark \quad \text { The promotion of the work collective is a guarantee of the mastery of quality production management } \\
\text { methods and the gain of a new clientele. } \\
\checkmark \quad \text { As far as we are concerned, we have various profiles in the fields of commerce and marketing. } \\
\checkmark \quad \text { I think that the fact that our finance department is managed by a team in perfect collaboration within } \\
\text { which there is perfect understanding, trust and respect, it has favored our economic and strategic } \\
\text { survival. } \\
\checkmark \quad \begin{array}{l}\text { Our action plan is developed by a working group made up of all the heads of departments, which is what } \\
\text { justifies its appropriation and acceptance by the majority. }\end{array} \\
\checkmark \quad \begin{array}{l}\text { Our collective develops shared vocabularies of collaborative work, which has made it possible to save } \\
\text { money and attract customers. }\end{array} \\
\checkmark \text { Within our network, there are shared memories that have contributed to the improvement of the } \\
\text { productive system. } \\
\text { We note, since the Covid-19 phenomenon, the existence of a common reference system and rules that have } \\
\text { played a decisive role in the strategic positioning in our competitive environment. }\end{array}$ \\
\hline
\end{tabular}

The analysis of the integral reports (Table 4) in the qualitative strategy, clearly shows the contribution of collective intelligence in the construction of collective competence and, therefore, entrepreneurial resilience. However, entrepreneurs interviewed reports that mutual support and sharing capacity have been instrumental in the resilience of entrepreneurs. While collaboration ignores collective competence but promotes entrepreneurial resilience. Table 5 shows the result.

On a descriptive and correlational level, we put forward the mean and standard deviation (sd) parameters. Thus, in general, the Cameroonian and Chadian entrepreneurs studied perceive (i) mutual support (SM) and (ii) sharing capacity (SC) as two factors in building a collective entrepreneurial competence, in the context of the Covid-19 pandemic. Indeed, they report having developed MS and SC that build collective competence (CC), respectively 4.7 out of $5(s d .=1.63)$ and 4.5 out of $5(s d .=1.58)$ averages. Entrepreneurs say they have developed these two postures, from the stage of announcing government measures to combat Covid-19. They mention that their collective intelligence concerns the aspects of innovation and execution of activities. Secondly, entrepreneurs say they have developed dynamic capacities (DC) by reorganizing resources to cope with the changes brought about by Covid-19. This DC, on the other hand, contributed little to entrepreneurial resilience, both economically and strategically, with an average of $2.6(\mathrm{sd} .=.93)$. Finally, the entrepreneurs interviewed said they had prioritized more of the collective competence, which played a decisive role in the economic and strategic survival of business during the Covid-19 pandemic, with an average of $4.8(\mathrm{sd} .=1.65)$. The results show that Cameroonian and Chadian entrepreneurs collaborate, support each other and share resources, at the local level but little in the inter-county level.

Finally, Table 5 also presents the strong correlational results between the variables. More specifically, mutual support has the strongest correlation $(r=0.96 ; \mathrm{p}<.01)$ and statistically positive with CC. Similarly, the sharing capacity is also the highly correlated variable $(r=0.91, \mathrm{p}<, 01)$ statistically positive with cc. On the other hand, dynamic capacity (DC) is positively but statistically nonsignificant correlated with entrepreneurial economic resilience (REE) $(r=0.043, p<.01)$ and strategic entrepreneurial resilience (SER) $(r=0.035, p<.01)$. Finally, the $\mathrm{CC}$ is positively associated with the EER $(\mathrm{r}=0.93, \mathrm{p}<.01)$ and the RES $(\mathrm{r}=0.89, \mathrm{p}<, 01)$. These results are consistent with most of the full reports from the semi-directive interviews in Table 4, which support two thirds of the research hypotheses. 
Table 5. Means, standard deviations and correlations between variables

\begin{tabular}{|l|c|c|c|c|c|c|c|}
\hline Variables & Average (sd.) & MS & SC & DC & CC & EER & SER \\
\hline Mutual support (MS) & $4.7(1.87)$ & 1 & & & & & \\
\hline Sharing capacity (SC) & $4.5(1.63)$ & $0.89^{* *}$ & 1 & & & & \\
\hline dynamic capacity (DC) & $2.6(1.01)$ & $0.51^{* *}$ & $0.44^{* *}$ & 1 & & & \\
\hline Collective competence (CC) & $4.6(1.53)$ & $0.83^{* *}$ & $0.67 * *$ & $0.45^{* *}$ & 1 & & \\
\hline $\begin{array}{l}\text { Entrepreneurial economic } \\
\text { resilience (EER) }\end{array}$ & $4.8(1.65)$ & $0.96^{* *}$ & $0.89^{* *}$ & 0.043 & $0.93^{* *}$ & & \\
\hline $\begin{array}{l}\text { Strategic entrepreneurial } \\
\text { resilience (SER) }\end{array}$ & $4.3(1.65)$ & $0.93^{* *}$ & $0.91^{* *}$ & 0.035 & $0.89^{* *}$ & $0.84 * *$ & 1 \\
\hline
\end{tabular}

$* * \mathrm{p}<, 01$

In conclusion, if each entrepreneurial community invests effectively in its collective intelligence during every hour of normal and/or crisis moments, it will withstand shocks of any kind.

To test the three hypotheses, we borrowed multiple regression with input of stepwise variables. This method of selecting the variables allows the verification of the variation of the coefficient of determination $\mathrm{R}^{2}$ of each explanatory variable added to the equation of the model according to Alain (2004). Table 6 shows the results.

\section{Hypothesis 1 (H1): Mutual support and sharing capacity increase collective competence.}

On the qualitative level, entrepreneurs are unanimous on their ability to share, support and snack to put forward collective intelligence during the covid-19 crisis:

[...] here, the degree of mutual support and our capacity for sharing has improved considerably through the capacity for collaboration, the level of pooling of our effort, and sharing material, informational resources has increased a lot since the covid-19 crisis, this is what explains the improvement in the collective competence of the staff. We have noticed the collective motivation for cooperative entrepreneurial action of women and young people mainly in the field of food security. [...], For this aspect (innovation) of collective intelligence, we note, for example, the establishment of spaces for the exchange of knowledge, common experiments of renewed methods and tools in the flow of production, distribution and sales in Cameroon and Chad, this is what participates in the construction of collective competence and promotes the revival of SME activities. But there is also a collective for actions to support accompanying persons for new and entrepreneurs in financial, organizational and strategic difficulties; this collective has helped save more than 5 SMEs since the advent of Covid-19. Finally, I note that during Covid-19, it is the level of pooling of entrepreneurs' knowledge that has made it possible to reorganize and revitalize several sectors of activity at the primary, secondary and tertiary levels. In my opinion, collective capacity has improved in the area of restaurants, bars, intercity transport, etc.

These revealing opinions testify to the effectiveness of collective intelligence as a factor contributing to the survival of entrepreneurs in times of crisis. However, a few entrepreneurs mentioned new factors not considered in the interview guide:

[...] in my opinion, we should also add, for example, human warmth and relational intelligence, which have played a decisive role in building collective competence, which in turn contributes to economic entrepreneurial resilience (REE) and strategic entrepreneurial resilience (SER) in Chad and Cameroon. These are very important aspects that must be taken into account because our profession needs solidarity rather than selfishness and confrontation.

Quantitatively, mutual support (MS) and sharing capacity (SC) significantly predicts collective competence (CC). Indeed, the values $\mathrm{R}^{2}$, which estimate the contribution of each variable to the proposed model, show that the contribution of the $\mathrm{SM}\left(\mathrm{R}^{2}=0.27, p<, 00\right)$ and the $\mathrm{SC}\left(\mathrm{R}^{2}=0.25, p<, 00\right)$ to the construction of $\mathrm{CC}$ is significant. In other words, the dynamic capacity (DC) and SC explain respectively $27 \%$ and $25 \%$ of the variation in the CC of entrepreneurs studied in Chad and Cameroon, during the covid-19 period. With regard to the standardized coefficient $\left(b_{\mathrm{SM}}=0.29\right.$ and $\left.\mathrm{b}_{\mathrm{CP}}=0.27\right)$, it means that with each improvement in the scale of the quality of the mutual support (MS) and the SC, the level of $\mathrm{cc}$ of entrepreneurs in Chad and Cameroon predicted increases. Similarly, the standardized beta coefficients $\left(\beta_{S M}=0.32\right.$ and $\left.\beta s_{C}=0.29\right)$, show that these variables contribute to the prediction of $\mathrm{CC}$ when considering an increase in the standard deviation of the variables. The T-test values 
$\left(t_{S M}=8.83\right.$ and $\left.t_{S C}=8.72 ; p<, 00\right)$ indicate that the contributions of the DC and SC to explaining the level of CC of the entrepreneurs studied are statistically significant. These results confirm hypothesis 1 on the prediction of the CC of entrepreneurs in Cameroon and Chad by DC and SC.

Hypothesis 2 (H2): Dynamic capacity positively influences entrepreneurial economic resilience (H2a) and strategic entrepreneurial resilience $(\boldsymbol{H} 2 \boldsymbol{b})$.

Qualitatively, it emerges from the opinion of the entrepreneurs' managers that:

[...] here, the practices of dynamic capacity that we think we can master and that is effectively deployed relate to the spirit of cooperation centered on trust, the pooling of experiences, the implementation of collaborative platforms, the reorganization of communication strategies, the promotion of collective work. Unfortunately, these practices do not make it possible to withstand the consequences of government measures to combat the covid-19 pandemic. It should be noted that we are not specialists in corporate strategy in times of crisis such as Covid-19 but we can reassure you that our collaboration strategy has not proven its worth and does not meet our expectations: our economic, financial and strategic survival does not result much from our intelligence in terms of collaboration.

These opinions testify to the ineffectiveness of collaboration as a relevant and effective posture that can generate entrepreneurial resilience in the context of a crisis.

Quantitatively, dynamic capacity (DC) weakly predicts both entrepreneurial economic resilience (EER) and strategic entrepreneurial resilience (SER). Indeed, according to the data in Table 6 , the coefficients $\mathrm{R}^{2}$ show low contributions $\left(\mathrm{R}^{2}=0.02\right.$ and $\left.\mathrm{R}^{2}=0.01, p<, 00\right)$ of the DC in the EER $\left(\left[\mathrm{R}^{2}=0.021 ; p<, 00\right]\right.$ and $\mathrm{SER}\left[\mathrm{R}^{2}=0.019\right.$, $p<, 00]$. In other words, the DC explains an additional $2.1 \%$ of the variation in the SER and $1.9 \%$ of the variation in the SER of entrepreneurs studied in Cameroon and Chad. The coefficients $[b=2.3$ and $b=2.1]$ mean that with each improvement in the quality scale of the DC, the levels of economic entrepreneurial resilience and strategic entrepreneurial resilience increase slightly. The same applies to the beta coefficients $[\beta=$ 3.6 and $\beta=2.3$ ]. The $\mathrm{T}$-test values [ $\mathrm{t}=6.36$ and $t=6.32]$ indicate that these contributions to the explanation of the level of EER and SER are of little significance. Such results do not confirm hypothesis 2.

Hypothesis 3 [H3]: Collective competence positively influences the entrepreneurial economic resilience of SMEs [H3a], as well as their strategic entrepreneurial resilience [H3b].

The results of the interview show that the collective competence factor increases both the entrepreneurial economic resilience [EER] and the strategic entrepreneurial resilience [SER] of entrepreneurs in Chad and Cameroon.

[...] He teams, we have significantly improved the distribution management capacity and therefore our circuit, this has allowed to increase the level of sales and therefore to win new customers. Similarly, the promotion of the work collective is a guarantee of the mastery of quality production management methods and the gain of a new clientele. As far as we are concerned, we have various profiles in the areas of commerce and marketing, which has contributed to the satisfaction of our customers and the gain of new markets; I think that the fact that our financial department is managed by a team in perfect collaboration within which there is perfect harmony, trust and respect, it has favored our economic and strategic survival. Our action plan is developed by a working group made up of all the heads of departments, which is what justifies its appropriation and acceptance by the majority. Our collective develops shared vocabularies of collaborative work, which has made it possible to save money and attract customers. Within our network, there are shared memories that have contributed to the improvement of the productive system. We note, since the phenomenon of Covid-19, the existence of a common reference and rules that have played a decisive role in the strategic positioning in our competitive environment. Finally, for us, the posture of solidarity, of common vision, of pooling knowledge, generates more productivity gains than confrontation and selfishness.

These opinions demonstrate the emergence of entrepreneurial resilience in times of crisis through the collective competence of economic operators.

Quantitatively, collective competence [CC] predicts both entrepreneurial economic resilience [EER] and strategic entrepreneurial resilience [SER]. Indeed, according to Table 6 , the $\mathrm{R}^{2}$ coefficients show significant contributions in the CC of the RESP $\left[\mathrm{R}^{2}=0.33 ; p<, 00\right]$ and $\operatorname{Res}\left[\mathrm{R}^{2}=0.32, p<, 00\right]$. In other words, the CC explains an additional $33 \%$ of the variation in the RES and $32 \%$ of the variation in the RES of the entrepreneurs studied in Cameroon and Chad. The coefficients $[b=0.35$ and $b=0.33]$ mean that with each improvement in the $\mathrm{CC}$ quality scale, the levels of entrepreneurial economic resilience and strategic entrepreneurial resilience increase. Similar results are observed for beta coefficients $[\beta=0.38$ and $\beta=0.36]$. The T-test values $[\mathrm{t}=8.36$ and 
$t=8.34]$ indicate that these contributions to the explanation of the level of EER and SER are significant. Such results confirm hypothesis 3 .

Table 6. Predictors of entrepreneurial resilience in the context of Covid-19

\begin{tabular}{|l|c|c|c|c|c|}
\hline Variables & $\mathbf{R}^{\mathbf{2}}$ & $\mathbf{b}$ & $\boldsymbol{\beta}$ & $\boldsymbol{y o u}$ & $\boldsymbol{p}$ \\
\hline Constant & & 2.17 & 2.37 & 8.62 & 0.00 \\
\hline Mutual support & 0.27 & 0.29 & 0.32 & 8.83 & 0.00 \\
\hline Sharing capacity & 0.25 & 0.26 & 0.29 & 8.72 & 0.00 \\
\hline Dynamic capacity & $\mathrm{EER}=0.02$ & $\mathrm{EER}=0.02$ & $\mathrm{EER}=0.04$ & $\mathrm{EER}=6.36$ & 0.30 \\
& $\mathrm{SER}=0.018$ & $\mathrm{SER}=0.019$ & $\mathrm{SER}=0.02$ & SER $=6.39$ & 0.20 \\
\hline Collective Competence & $\mathrm{EER}=0.33$ & $\mathrm{EER}=0.35$ & EER $=0.38$ & EER $=8.36$ & 0.00 \\
& $\mathrm{SER}=0.32$ & $\mathrm{SER}=0.33$ & SER $=0.36$ & SER $=8.34$ & 0.00 \\
\hline
\end{tabular}

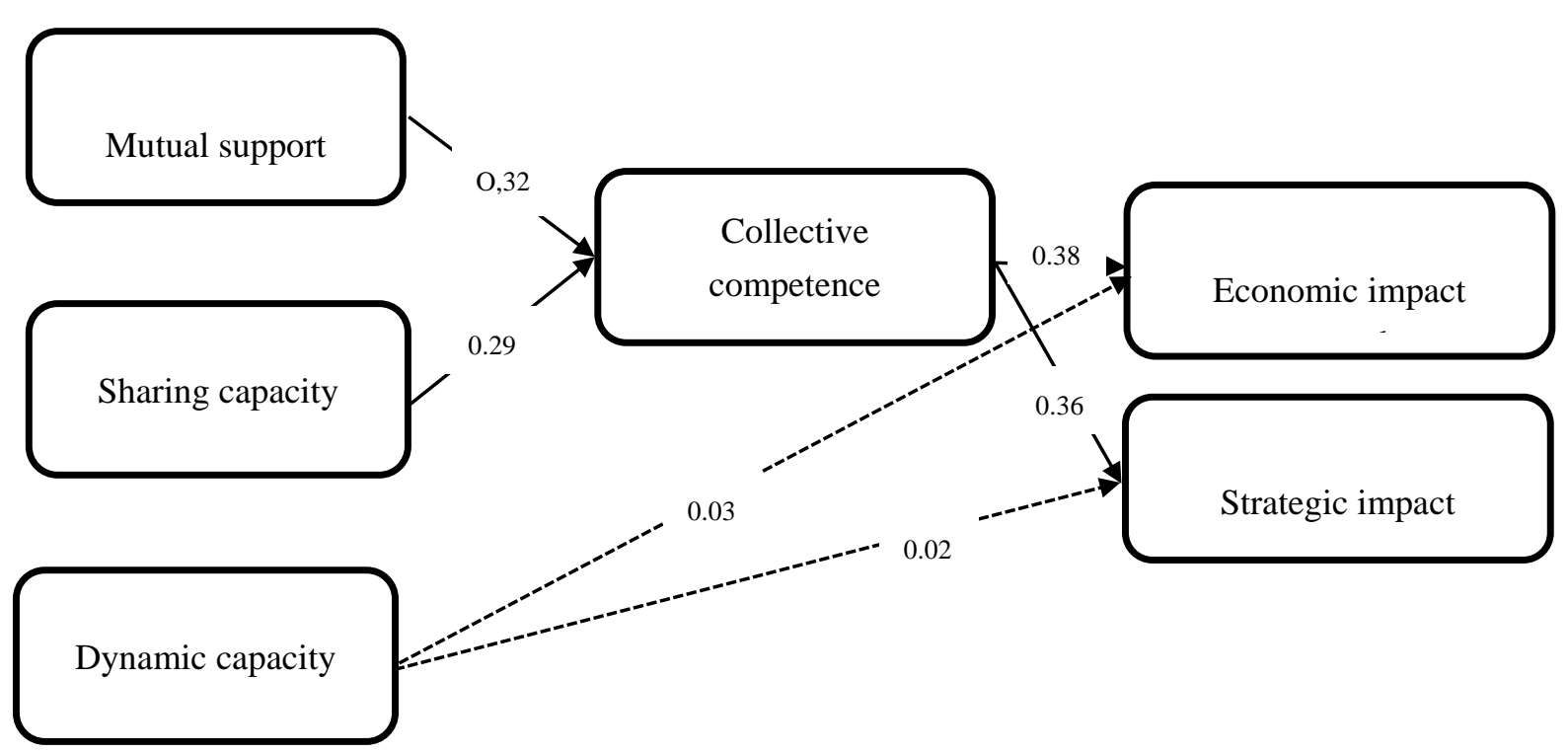

Figure 3. Main factors of economic and strategic resilience of the entrepreneurs studied

\subsection{Discussion}

The study aimed to assess the impact of collective intelligence on the entrepreneurial resilience of Cameroonian and Chadian economic operators during the period of the Covid-19 pandemic. In general, the results of this study show that collective intelligence, to increase entrepreneurial resilience, generates, beforehand, collective competence, which contributes to the economic and strategic rebound of entrepreneurs. These results are significantly in line with previous work (Akgüna \& Keskina, 2015).

Specifically, based on qualitative and quantitative results, mutual support (MS) and sharing capacity (SC) is associated, positively and statistically significant, with collective competence (hypothesis 1). Similarly, they improve and contribute significantly to the prediction of collective competence (CC). Such results are not fortuitous. Indeed, the mutual support (MS) and the sharing capacity (SC), according to the words of several theorists and practitioners of collaborative management (Henri \& Lundgren-Cayrol, 2001) are, through collaborative work, mechanisms of sharing, support, flexible communication, etc. means that make it possible to respond to daily reactions and problems in the context of unpredictability (Ayala \& Manzano, 2014; Bahadori, 2012; Boughzala, 2020; Bullough \& Renko, 2013; Carlier, 2016). These results can also be explained by the fact that the pooling of knowledge, but also collective commitment is effective ways of working by which economic operators can achieve better collective performance resulting from collective competence. Collective work through the full integration of competitive human capital (Mignenan, 2020b) promotes, for entrepreneurs in 
crisis situations or not, the increase of resilience in its economic and strategic dimensions. It helps to break the unyielding selfishness and confrontation with an ever-changing environment. For SMEs, which are expected to survive in a context of crisis, MS and SC allow the common conception of the future portrait through joint reflection and action. It is one of the keys means of economic and strategic resistance of SMEs and their positioning in an unstable context (Samiha \& Brahim, 2020; Valencia et al., 2015; Woolley et al., 2015)

Consequently, regular investments in DC and CP are a strategy to achieve collective competence (CC) in order to achieve an economic rebound. These results corroborate the perspectives of the current of thought of collaborative management but also they are similar to those obtained by previous work (Chédotel \& Krohmer, 2014; Defélix et al., 2014; Michaux, 2005; Saur-Amaral, 2010; Ünay \& Zehir, 2012) Indeed, according to the results of these authors, the improvement in the quality of collective intelligence predicts collective competence, which generates entrepreneurial resilience. However, some of our empirical qualitative results do not converge much with the literature because the implementation of collaborative management, the support of collective intelligence, is based on the values of human capital, in particular trust, motivation, solidarity, etc. (Henri \& Lundgren-Cayrol, 2001).

Second, dynamic capacity (DC) positively but statistically insignificant influences entrepreneurial economic resilience (EER) and strategic entrepreneurial resilience (SER) (hypothesis 2). Such a result is surprising considering that DC plays an important role in terms of reorganizing resources for better adaptation of an unpredictable ecosystem (Altintas, 2015; Mathé, 2006; Pierre \& Fernandez, 2018). For example, DC does not effectively contribute to reducing risks, waste, and waste of time in the process of implementing entrepreneurial projects. Such results do not confirm those obtained by several authors in a different context (Altintas, 2015; Ambrosini \& Bowman, 2012; Mathé, 2006; Pierre \& Fernandez, 2018; TEECE et al., 1997) Moreover, the fact that $\mathrm{CD}$ does not appear as a significant predictor of entrepreneurial resilience does not find its justifications in the current of collaborative management, nor in organizational theology but earlier in the protocols for combating Covid-19 which do not promote interaction.

Finally, collective competence (CC) promotes economic entrepreneurial resilience (EER) and strategic entrepreneurial resilience (SER). Such an outcome is not surprising considering that the pooling of capacities and the dynamic integration of skill profiles plays an extremely important role in achieving greater resilience of economic operators in an uncertain environment. This pooling of forces pursuing a single shared objective is a lever of trust and motivation of the actors. The CC introduced as a mediating variable between mutual support, sharing capacity but also the EER and the SER, is a strategic response to environmental fluctuations due to the Covid-19 crisis. Our results are similar to those in the literature that reports that $\mathrm{CC}$ rhymes with creativity, innovation, mobility and responsiveness (Boughzala, 2020; Boutigny, 2004; Brulhart et al., 2019; Carlier, 2016; Defélix et al., 2014; Dufresne \& Peyrat-Guillard, 2009; Dupuich, 2011; Foudriat, 2014). SMEs developing CC posture can cope, quickly but effectively, with the constraints due to changes in the environment. Similarly, these results are also explained by the fact that $\mathrm{CC}$ rhymes with agility, which conveys values and principles conducive to the motivation, trust and commitment of actors in collaborative work (Henri \& Lundgren-Cayrol, 2001).

In the light of the above, it should be stressed that the impact of collective intelligence through collective competence on entrepreneurial resilience, in the context of crisis, is independent of the economic situation of the country and the sectors of entrepreneurs studied. Rather, it depends on the perspective of collaborative management on which the collective intelligence of entrepreneurs is based, considered as a means of creativity, innovation and therefore resistance and not as an end or resource of production. The second explanation related to these results is that entrepreneurial resilience is a cognitive concept inserted into a corpus of various theories, but also a posture that usually manifests itself in a situation of complexity in the field of maneuvers. As the results show so well, the conceptual model of this study is part of the action. It is therefore constructed in such a way that a collective way of working (collaboration, cooperation, etc.), for the benefit of entrepreneurs in a crisis situation, is understandable both for the actor himself and for the purpose of his entrepreneurial project. This perspective corroborates the framework of current interpretation of the entrepreneur's daily life as a subject vulnerable to more risks if he evolves in a closed vacuum.

On the basis of the elements of the discussion, it is necessary to consider theoretical, methodological and managerial implications, to highlight the limits and to suggest future avenues. The following lines report the results. 


\subsection{Implication of This Study}

\subsubsection{Theoretical Contribution}

Our article aims to contribute to the advancement of studies on entrepreneurial resilience (ER) in the context of crisis as a result of collective intelligence (CI). The components of collective intelligence resilience (CIR) put forward by previous scientific studies concern, for the most part, stable contexts. While the tested relationships between the components of the CIR and entrepreneurial resilience (ER) are limited only to this level. Similarly, the relationships tested are all direct. Previous research has also led to the conclusion that collective intelligence participates effectively in entrepreneurial resilience without explicitly mentioning the theoretical framework that supports the words. Thus, the decomposition of collective intelligence, the introduction of the mediating variable but also the salami-slicing of entrepreneurial resilience has not been carried out. The same applies to formally explicit definitions of key concepts. Thus, the main theoretical contribution of this study is to have introduced, in the theoretical model, mutual support (MS), sharing capacity (SC), dynamic capacity (DC), collective competence (CC), economic entrepreneurial resilience (EER) and strategic entrepreneurial resilience (SER). It is above all the mobilization of the theory of collaborative management to explain the results that constitute the major theoretical contribution. Similarly, we have proposed a definition of CIR and ER don't the need for improvement still remains.

In addition, we have shown that, in the process of entrepreneurial resilience in crisis situations, collective competence, resulting from collective intelligence, has a strong explanatory power over the economic and strategic rebounds of entrepreneurs. In other words, highlighting the benefits of collaborative management plays a decisive role in the survival of entrepreneurial projects. Conversely, a mechanical management mode inhibits collaboration, sharing and integration of skills, a guarantee of performance and therefore resilience. This research shows that, beyond the DC and the SC, we should not, however, ignore the DC, as a process of reorganization of resources, which could, at a minimum, improve the EER and the SER.

Finally, this study brings out new avenues s theoretical. Indeed, the identification and testing of new variables, in particular "collective competence" and "dynamic capacity" constitute the contribution to the valorization of collective intelligence as a means of survival of entrepreneurship projects. This approach, of which the conceptual model developed is the manifestation, had not been the subject of research that applied a rigorously empirical mixed estimate. It thus emerges that the entrepreneurs, in the context of crisis, so that he is resilient, are invited to invest in their dynamic capacities and they our practices of collective competence based on collaborative management. Consequently, in addition to collaborative management, two other theoretical avenues should be added, in particular participatory management theory and organizational theory. Proponents of this current of thought put forward sharing, integration, fluid communication and the importance of reorganizing resources as a strategy for active and productive competitiveness.

\subsubsection{Methodological Contribution}

The deployment of the simultaneous mixed method is part of the asset of the major methodological contribution. Specifically, the identification of more than five new constructs and the adaptation of the contents of the items explaining mutual support (MS), sharing capacity (SC), dynamic capacity (DC), etc. represent a relevant methodological contribution, because previous research has not taken into account these constituents specific to the subject of their studies. In addition, the hypothetico-deductive posture borrowed made it possible to highlight the items formulated in the context of the present study.

Secondly, it should be noted that the correlational and explanatory analyses have made it possible to prove the reliability and relevance of several items. These include: (i) dynamic peace; (ii) resource sharing; (iii) capacity integration; (iv) the pooling of forces; (v) the shared memory. These are items that have been defined as part of this research. Thus, the reliability and relevance of these items are part of the range of remarkable methodological contributions.

Finally, the mixed estimate applied is an undeniable methodological contribution. Indeed, this approach has made it possible to reduce the limitations shown by qualitative and quantitative approaches. It is a strategy that has facilitated a finer and more complete understanding of the issue of entrepreneurial resilience in the context of a crisis. This methodology was applied in one step in which both types (qualitative and quantitative) of data were produced simultaneously and iteratively. In addition, the side-by-side analysis of the combination of the mixed approach made it possible to document concepts that were little studied, including "mutual support," "sharing capacity" and "economic and strategic entrepreneurial resilience." 


\subsubsection{Practical Contributions}

The identification of the factors "collective skills" and "collective intelligence", which have a significant impact on economic and strategic entrepreneurial resilience, represents a concrete managerial contribution for all Cameroonian and Chadian entrepreneurs and partners working for entrepreneurial development. Indeed, highlighting the positive and statistically significant links between collective competence (CC) and entrepreneurial resilience is an indispensable point on which Cameroonian and Chadian economic operators, consultants, researchers, banking institutions and governments can relate to formulate and enrich new strategies for entrepreneurial promotion.

Similarly, this research has highlighted the strong explanatory power of CC mediate mutual support (MS) and sharing capacity (SC) but also dynamic capacity (DC) on entrepreneurial resilience. Even if some opinions revealed difficulties due to trust, motivation and commitment, this research suggests that entrepreneurs bet on synergy, solidarity, interactivity, integration of capacities, networking in their entrepreneurial practice earlier than selfishness and confrontation. Specifically, it is desirable that the focus be on the different dimensions of collecting competence and therefore collective intelligence to promote the sustainability of their entrepreneurial project.

Be that as it may, this research has made it possible to show that the combination of growth assets (human capital), the union of forces, resources, the integration of knowledge, commitment and collective experimentation are an appropriate trajectory to generate the overall performance and survival of the entrepreneurial project in a context of complexity. This result is fundamental for entrepreneurs whose vulnerability is proven but also who would have to face the unpredictability of the ever-changing environment.

\subsubsection{Limitations and Future Directions}

Despite the contributions, this research also has limitations. First, the results of our research are based on information provided by a sample of 282 entrepreneurs, 173 in Cameroon and 109 in Chad, who survived despite government measures due to the covid-19 pandemic. Compared to several other studies conducted on entrepreneurial resilience, our study produces fairly similar results, namely that the relationship between collective intelligence and entrepreneurial resilience is positive and statistically significant. However, this result must be considered with reservations when it is generalized to other contexts and to the two territories as a whole, which is a field of maneuvers for our three hypotheses. In our view, the results obtained are much more dependent on the ecosystem of our respondents' localities and the sample, which appears to be small in size. It would therefore be useful to study more than five cities per country at the same time and with the larger size. The second limitation is related to the fact that the covid-19 crisis and its consequences are still noticeable and therefore the majority of entrepreneurs are still experiencing traumatization. Thus, a longitudinal approach, integrating failed entrepreneurs and those who survive, are needed in future research. In addition, several relevant topics are left for future studies. This study leaves us convinced that the promotion of collective intelligence through the collective integration of knowledge from all disciplines, mutual trust, organized teams, fluid and flexible communication, etc. increase entrepreneurial resilience in a complex situation; this has been proven by our study. Future research could look at these aspects while introducing other variables, such as emotional intelligence, relational intelligence, relational competence in its different dimensions and moderating variables in the theoretical model, etc. Finally, a confirmatory analysis by the structural equation model would shed light on the robustness of the relationships.

\section{Conclusion}

This study focuses on the influence of collective intelligence on collective competence and entrepreneurial resilience in the context of Covid-19. It emerges that thanks to the theoretical anchoring of collaborative management, content analyses and lexical analysis as well as regression analyses conducted, respectively on a sample of 15 executive entrepreneurs and 282 entrepreneurs, we have developed and tested a conceptual model whose results show that "mutual support" and "sharing capacity" are postures by which the entrepreneurs studied manage to build their collective competence in the era of the Covid-19 pandemic. This collective competence is the lever of economic and strategic entrepreneurial resilience. On the other hand, the "dynamic capacity" seems not very effective for the entrepreneurs studied and the context of the study for reasons, strictly instrumental due to the pandemic.

Our findings contrast with previous research focused on resilient entrepreneurship in a crisis context. They lead us to stress the importance of continuing research on the subject, and in particular to reconsider the dynamic capacity of entrepreneurs and to draw comparisons between entrepreneurs in a crisis context and those evolving in a stable ecosystem, and between countries. Be that as it may, entrepreneurs who survive are thanks to their 
collective intelligence, thus putting forward the surge of solidarity, the pooling of knowledge via human capital and relational capital as a heritage of innovation. On the other hand, they ignore the confrontation and selfishness.

\section{References}

Akgüna, A., \& Keskina, H. (2015). Organisational resilience capacity and firm product innovativeness and performance. International Journal of Production Research, 52(23), 6918-6937. https://doi.org/10.1080/00207543.2014.910624

Alphonse-Tilloy, I., \& Altintas, G. (2018). Processus de formation d'une capacité dynamique : le cas d'une petite entreprise internationale. Revue internationale P.M.E., 31(1), 23-58. https://doi.org/10.7202/1044688ar

Altintas, G. (2015). Le rôle des capacités dynamiques dans la création et le renforcement d'une compétence organisationnelle: le cas d'un tour-opérateur géré par des dirigeants-actionnaires. Management international, 20(1), 39-51. https://doi.org/10.7202/1045354ar

Ambrosini, V., \& Bowman, C. (2012). What are dynamic capabilities and are they a useful construct in strategic management? International Journal of Management Reviews, 11(1), 29-49. https://doi.org/10.1111/j.1468-2370.2008.00251.x

Amhag, L., \& Jakobsson, A. (2009). Collaborative learning as a collective competence when students use the potential of meaning in asynchronous dialogues. Computers \& Education, 52(2009), 656-667. https://doi.org/10.1016/j.compedu.2008.11.012

Ayala, J.-C., \& Manzano, G. (2014). The resilience of the entrepreneur. Influence on the success of the business. A longitudinal analysis. Journal of Economic Psychology(2014), 1-10.

Bahadori, M. (2012). The Effect of Emotional Intelligence on Entrepreneurial Behavior: A Case Study in a Medical Science University. Asian Journal of Business Management, 4(1), 81-85.

Bernard, M. J., \& Barbosa, S. D. (2016). Résilience et entrepreneuriat: Une approche dynamique et biographique de l'acte d'entreprendre. Management, 19(2), 89-123. https://doi.org/10.3917/mana.192.0089

Boder, A. (2006). Collective intelligence: a keystone in knowledge management. Journal of Knowledge Management, 10(1), 81-93. https://doi.org/10.1108/13673270610650120

Boughzala, Y. (2020). Vers une approche collective de l'innovation sociale : le rôle joué par l'entrepreneuriat social en Tunisie Innovations. Innovations, 2(62), pages 161 à 189. https://doi.org/10.3917/inno.062.0161

Boutigny, E. (2004). Coopération dans l'entreprise et compétence collective. XVème congrès de l'AGRH, Sep 2004, Montréal, Canada.(2020), 1328-1344.

Brulhart, F., Favoreu, C., \& Loufrani-Fedida, S. (2019). L'influence de la compétence collective sur la performance d'équipe : analyse du rôle modérateur du leadership partagé et du coaching. Management international, 23(4), 150 à 164. https://doi.org/10.7202/1066076ar

Bullough, A., \& Renko, M. (2013). Entrepreneurial resilience during challenging times. Kelley School of Business, 56(2013), 343-350. https://doi.org/10.1016/j.bushor.2013.01.001

Bullough, A., Renko, M., \& Myatt, T. (2014). Danger Zone Entrepreneurs: The Importance of Resilience and Self-Efficacy for Entrepreneurial Intentions. Entrepreneurship theory and practice (2014), 473-499. https://doi.org/10.1111/etap.12006

Burnard, K., \& Bhamra, R. (2011). Organisational resilience: development of a conceptual framework for organisational responses International Journal of Production Research, 49(18), 5581-5599. https://doi.org/10.1080/00207543.2011.563827

Carlier, A. (2016). Management des projets collaboratifs: construire, développer et mettre en oeuvre. afnor.

Chédotel, F., \& Krohmer, C. (2014). Les règles, leviers de développement d'une compétence collective - deux études de cas. De Boeck Supérieur | «GRH », 3(12), pages 15-38. https://doi.org/10.3917/grh.012.0015

Creswell, J. (2013). Research Design: Qualitative, Quantitative, and Mixed Method Approaches (4th ed.)Sage, 4(2013), 1-285.

Davoudi, S. (2013). Resilience: A Bridging Concept or a Dead End? Planning Theory \& Practice, 13(2), 299-333. https://doi.org/10.1080/14649357.2012.677124 
Defélix, C., Boulaire, M. L., Monties, V., \& Picq, T. (2014). La compétence collective dans le contexte de la globalisation du management: retrouver le lien avec la performance. De Boeck Supérieur/GRH, 2(11), 31 à 50. https://doi.org/10.3917/grh.142.0031

Dufresne, D., \& Peyrat-Guillard, D. (2009). La compétence collective: une approche par l'analyse de ses traces textuelles. Université d'Angers -GRANEM UMR-MA N49, 2009(49), 1-24.

Dupuich, F. (2011). L'émergence des compétences collectives, vers une gestion durable. Gestion 2000, 28(2), pages 107 à 125. https://doi.org/10.3917/g2000.282.0107

Evrard, Y., Pras, B., Roux, E., Desmet, P., Dussaix, A. M., \& Lilien, G. (2009). Market - Fondements et méthodes de recherches en marketing.

Foudriat, M. (2014). Chapitre 13: La co-construction Une option managériale pour les chefs de service dans Le management des chefs de service dans le secteur social et médico-social cairn (Dunod), 2014, 229 à 250. https://doi.org/10.3917/dunod.delal.2014.01.0229

Henri, F., \& Lundgren-Cayrol, K. (2001). Apprentissage collaboratif à distance pour comprendre et concevoir les environnements d'apprentissage virtuels. presses de l'université du QUÉBEC(2001), 205 p.

Leimeister, J. M. (2010). Collective Intelligence. Business \& Information Systems Engineering, 4(2010), 245-248. https://doi.org/10.1007/s12599-010-0114-8

Levy, P. (2015). Collective Intelligence for Educators. Educational Philosophy and Theory, 47(8), 749-754. https://doi.org/10.1080/00131857.2015.1053734

Lévy, P. (2003). Le jeu de l'intelligence collective. Sociétés, 1(79), 105-122. https://doi.org/10.3917/soc.079.0105

Love, J., \& Roper, S. (2015). SME innovation, exporting and growth: A review of existing evidence. International Small Business Journal, 33(1), 28-48. https://doi.org/10.1177/0266242614550190

Malone, T., \& Bernstein, M. (2015). Handbook of Collective Intelligence. Massachusetts Institute of Technology, $2015,1-230$.

Mathé, J. C. (2006). Capacités dynamiques et reconfiguration stratégique des groupes pharmaceutiques Jean-Charles Mathé. La Revue des Sciences de Gestion, 2(218), 73-86. https://doi.org/10.3917/rsg.218.0073

Matlay, H., \& Westhead, P. (2007). Innovation and collaboration in virtual teams of e-entrepreneurs Case evidence from the European tourism industry. Entrepreneurship and innovation, 8(1), 29-36. https://doi.org/10.5367/000000007780007353

Michaux, V. (2005). Performance collective et compétences individuelle, collective et organisationnelle : construction d'une grille d'analyse unifiée. 16ème Conférence de l'AGRH-Paris Dauphine-15 et 16 septembre(2005), 1-26.

Mignenan, V. (2020a). Proposition d'un modèle de construction du capital humain en milieu organisationnel. Revue Ad-Machina, 4(2020), 110-134. https://doi.org/10.1522/radm.no4.1247

Mignenan, V. (2020b). Proposition d'un modèle de construction du capital humain en milieu organisationnel. Ad machina, 4, 110-134. https://doi.org/10.1522/radm.no4.1247

Mulgan, G. (2018). How Collective intelligence can change our world. Princeton University Press, New Jersey, United States of America, $283 \mathrm{p}$.

OIT. (2020). le COVID-19 et le monde du travail. Cinquième édition Estimations actualisées et analyses. Observatoire de l'OIT, 1-26.

Omrane, A., Fayolle, A., \& Ben-Slimane, O. Z. (2011). Les compétences entrepreneuriales et le processus entrepreneurial : une approche dynamique. Revue des Sciences de Gestion, 5(251), pages 91-100. https://doi.org/10.3917/rsg.251.0091

ONU. (2020). Impact socio-économique de la covid-19 au Gabon. ONU(2020), 1-52.

Pierre, A., \& Fernandez, A. S. (2018). Capacités dynamiques et innovation en PME : analyse d'un cas d'échec. Revue internationale P.M.E., 31(3/4), 131-165. https://doi.org/10.7202/1054421ar

PNUD. (2020). Effets socioéconomiques potentiels du Covid - 19 au Cameroun Une évaluation sommaire. Rapport PNUD, 1-29. 
Pquet, A. (2009). Guide pratique du travail collaboratif: Théories, méthodes et outils au service de la collaboration. Télécom Bretagne(2009), 1-80.

Remon, D. (2012). Innovation ouverte et capacités dynamiques : préparation à la collaboration internationale des PME. Innovations, 3(39), 71 à 98. https://doi.org/10.3917/inno.039.0071

Samiha, L., \& Brahim, B. (2020). Compétences, entrepreneuriat et performance: quelle dynamique pour le territoire?Skills entrepreneurship and performance: what dynamic for the territory? Revue Française d'Economie et de Gestion, 1(4), 344-366.

Saur-Amaral, I. (2010). Innovation intelligence: crowdsourcing in a social network Int. J. Technology Intelligence and Planning., 6(3), 288-299. https://doi.org/10.1504/IJTIP.2010.035780

Teece, D., Pisano, G., \& Shuen, A. (1997). Dynamic capabilities and strategic management. Strategic Management Journal, 18(7), 509-533. https://doi.org/10.1002/(SICI)1097-0266(199708)18:7<509::AID-SMJ882>3.0.CO;2-Z

Ünay, F. G., \& Zehir, C. (2012). Innovation intelligence and entrepreneurship in the fashion industry. Procedia Social and Behavioral Sciences, 41(2012), 315-321. https://doi.org/10.1016/j.sbspro.2012.04.036

Valencia, E. S., Roberto, V. B., \& Garcia, Z. Á. (2015). Collective intelligence: analysis and modelling. Kybernetes, 44(6/7), 1122-1133. https://doi.org/10.1108/K-11-2014-0245

Walker, J., \& Cooper, M. (2011). Genealogies of resilience: From systems ecology to the political economy of crisis adaptation. Security Dialogue, 42(2), 143-160. https://doi.org/10.1177/0967010611399616

Woolley, A. W., Aggarwal, I., \& Malone, T. (2015). Collective Intelligence and Group Performance. Psychological science, 6(24), 420-424. https://doi.org/10.1177/0963721415599543

Zaïbet, G. O. (2007). Vers l'intelligence collective des équipes de travail : une étude de cas. management \& avenir, 4(14), 41-59. https://doi.org/10.3917/mav.014.0041

\section{Copyrights}

Copyright for this article is retained by the author(s), with first publication rights granted to the journal.

This is an open-access article distributed under the terms and conditions of the Creative Commons Attribution license (http://creativecommons.org/licenses/by/4.0/). 